\title{
Hygienic health risk distribution due to atmospheric air pollution in low-lying cities
}

\author{
A.V. Kosarev ${ }^{1, *}$, N.E. Komleva ${ }^{1,2}$, S.V. Raikova ${ }^{1,2}, V . N$. Dolich $^{1}$, and I.V. Zaikina ${ }^{1}$ \\ ${ }^{1}$ Saratov Hygiene Medical Research Center of the Federal Budget Scientific Institution «Federal \\ Scientific Center for Medical and Preventive Health Risk Management Technologies», 410022, \\ Saratov, Zarechnaya, 1a, Russian Federation \\ ${ }^{2}$ Saratov State Medical University named after V.I. Razumovsky, 410012, Saratov, Bolshaya \\ Kazachya, 112, Russian Federation
}

\begin{abstract}
The total excess of components which pollute the atmospheric air of the city of Saratov has been increasing from May to October and is most evident for the locations of transport interchanges. The allocation of polluting components of atmospheric air corresponds to the distribution model of structural basin cities. The hazardous level of non-carcinogenic health risk caused by inhalation of substances polluting the atmospheric air of Saratov (HQ>1) is determined by the existence of nitrogen oxides, hydrogen sulfide, ammonia, and formaldehyde. Non-carcinogenic risk of hazard has a tendency to increase in the warm season - from May to July), as well as in the winter period (January-February). The carcinogenic health risk associated with the existence of formaldehyde in the air exceeds the upper limit of the permissible risk. The highest values of the carcinogenic risk match the monitoring points situated near motorways. This may be due to photochemical processes involving the results of incomplete fuel combustion in engines, in which formaldehyde is formed. The anticipated increase in respiratory morbidity due to chronic inhaled exposure to NO2 in children aged 6-7 years ranges from 44 to 79 percent, while the grow-up rates are higher in girls.
\end{abstract}

\section{Introduction}

Today, air pollution is regarded as the main environmental cause of various diseases and premature mortality in the world. The content of pollutants in the air affects the body's resistance, becoming more vulnerable to pathogens of various origins. Nitrogen oxides, benz[a]pyrene, formaldehyde, hydroxybenzene and its derivatives, chlorine and its compounds, hydrogen fluoride, hydrogen sulfide, ammonia, dust, carbon monoxide and other compounds remain priority risk factors for public health [1].

In 2018, on the territory of the Russian Federation, the number of extra deaths from all causes related to air pollution in residential areas was 1.6 cases per 100 thousand of the population. The main part of these deaths was caused by respiratory diseases $(1.8 \%)$ and

* Corresponding author: aleteia@inbox.ru 
malignant neoplasms $(0.4 \%)$ due to exposure to pollutants containing in the atmospheric air [1].

The study on the relative risks of major air pollutants for the development of respiratory and cardiovascular diseases, performed in Beijing from 2015 to 2017, revealed that the greatest damage to health is caused by PM10, PM2.5, and NO2 [2]. The ESCAPE (European Study of Colors for Air Pollution Effects) research revealed that air pollutants are the reason for lung cancer [3]. According to the meta-analysis, a positive correlation was found between the daily levels of priority air pollutants, such as PM10, PM2. 5, SO2, $\mathrm{NO} 2, \mathrm{CO}$, and the incidence of pneumonia in children [4].

One of the most hazardous pollutants is nitrogen dioxide (NO2). Nitrogen dioxide and nitric oxide (NO) in the atmosphere occur together. Therefore, their combined impact on the human body is most often estimated. Nitrogen dioxide improves the resistance of the respiratory tract, reduces the content of hemoglobin in the blood, lowers the resistance to diseases, tissue hypoxia, and also enhances the effect of carcinogenic substances.

Long-term exposure to NO2 is recognized to be related to a higher risk of mortality from diseases of the cardiovascular and respiratory systems [5], in particular from COPD [6] and bronchial asthma (BA) [7].

Recently, there have been reports that PM2. 5, NO2, and to a lesser extent PM10 are triggers for the spread and mortality from the novel coronavirus infection COVID-19 [8], for example, the relationship between the level of nitrogen dioxide in the air and mortality from COVID-19 [9].

One of the controlled pollutants at air quality monitoring points is sulfur dioxide (SO2). The main impact of SO2 is on the respiratory system, both in chronic and acute exposure [10]. Combined exposure to PM10 and SO2 significantly enhances the chances of asthma in children in the first five years of life [11].

Hydrogen sulfide (H2S) is one of the most harmful gases with an unpleasant smell. Chronic exposure to low concentrations of hydrogen sulfide results in the suppression of the sympathetic nervous system function [12], promotes disorders of the cardiovascular, respiratory, and digestive systems, as well as metabolic disorders [13].

Phenol contained in atmospheric air is a hazard factor for the development of chronic diseases of the respiratory system [14], the endocrine system [15]. It affects the reproductive function and leads to the development of metabolic syndrome [16].

Formaldehyde in the atmospheric air of low-lying cities is a product of photo-oxidation of hydrocarbons produced as a result of incomplete fuel combustion, and a typical component of smog in low-lying cities. Owing to its high reactive chemical activity, formaldehyde is capable of changing the course and intensity of metabolic processes, causing damage to DNA and protein molecules in human cells [17], having mutagenic, carcinogenic, teratogenic, general toxic, sensitizing and allergenic effects [18]. It is revealed that the content of formaldehyde in the atmospheric air relates to the development frequency of the bronchial asthma [19].

Therefore, numerous analyses prove that atmospheric air pollution forms a carcinogenic and non-carcinogenic risk of developing health disorders. The pollution distribution in the atmospheric air of cities located in lowlands depends on the altitude. In this regard, the issue of determining the health risks caused by the impact on the body of pollutants in the atmosphere of low-lying cities, depending on the altitude above sea level, is topical.

The purpose of the study is to - to assess the carcinogenic and non-carcinogenic health risks resulting from inhaled atmospheric air intake in Saratov. For achievement of the specified goal the following tasks were solved:

a) determination of the altitude of monitoring points for atmospheric pollution in the city of Saratov above sea level; 
b) average doses obtained by the body when inhaling priority air pollutants: $\mathrm{SO} 2, \mathrm{NO}$, $\mathrm{NO} 2, \mathrm{H} 2 \mathrm{~S}, \mathrm{HCHO}, \mathrm{C} 6 \mathrm{H} 5 \mathrm{OH}$, dust, as well as the hazard index due to the total effect of these components.

c) carcinogenic health risk assessment due to inhaled intake of the main atmospheric air pollutants in the city of Saratov into the human body.

\section{Materials and methods}

Due to the presence of the i- polluting component in the atmospheric air, the hazard ratio $\mathrm{HQ}_{\mathrm{i}}$, is defined by the ratio:

$$
H Q_{i}=\frac{L A D D_{i}}{R f D_{i}}
$$

Here $\mathrm{LADD}_{\mathrm{i}}$ - the value of the average daily dose of the i- polluting component in water ( $\mathrm{mg} / \mathrm{kg}^{*}$ day) is determined; RfDi - reference dose $(\mathrm{mg} / \mathrm{kg}$ ) for chronic inhalation exposure, determined by the ratio [20]:

$$
L A D D_{i}=\frac{C_{i} \cdot C R \cdot E D \cdot E F}{B W \cdot A T \cdot 365},
$$

where $\mathrm{Ci}$ - concentration of $\mathrm{i}$ - polluting component in the atmospheric air $\left(\mathrm{mg} / \mathrm{m}^{3}\right), \mathrm{CR}$ - daily air consumption (20 $\mathrm{m}^{3} /$ day), ED - exposure duration (years), EF - exposure frequency (days/year), BW- average body weight (70 kg), AT - exposure averaging period (years).

The reference concentration of RfCi and the reference dose of RfDi are correlated with each other by the ratio:

$$
R f D_{i}=\frac{R f C_{i} \cdot C R}{B W}
$$

Non-carcinogenic risk matches the acceptable level if $\mathrm{HQ}<1,0$; is the maximum permissible if $\mathrm{HQ}=1,0$, it is a non-carcinogenic risk; it is hazardous if $\mathrm{HQ}>1,0$.

The total index HI of the hazard caused by the introduction of several atmospheric air pollutants into the body was defined by the formula:

$$
H I=\sum_{i} H Q_{i},
$$

The individual carcinogenic risk caused by the existence of $i-$ in the atmospheric air was estimated using the formula:

$$
R_{i}=1-\exp \left(-L A D D_{i} \cdot S F_{0 i}\right)
$$

where $\mathrm{SF}_{0 \mathrm{i}}$ - the potential value of the carcinogenic risk resulting from exposure to the i- substance on the body $(\mathrm{kg} \cdot \mathrm{day} / \mathrm{mg})$.

The increase in the respiratory system morbidity due to chronic inhaled exposure to NO2 in children was estimated according to the ratio [21]:

$$
Y=\frac{1}{1+\exp (0,536-0,0275 C(N O 2)+0,0295 k)},
$$


where $\mathrm{k}=0$ for women, $\mathrm{k}=1$ for men.

The data on the concentrations of the main air pollutants for the period from March 2020 to March 2021 in the city of Saratov were used in the paper according to the data of Saratov Center for Hydrometeorology and Environmental Monitoringhttp://pogodasv.ru/monitoring/ecology_aero/sar/sar.php.

\section{Results and discussion}

The distribution by altitude of the pollution monitoring posts (PMP) in the city of Saratov, for which the analysis of non-carcinogenic and carcinogenic health risks resulting from the inhaled intake of polluting components was conducted, is shown in Figure 1.

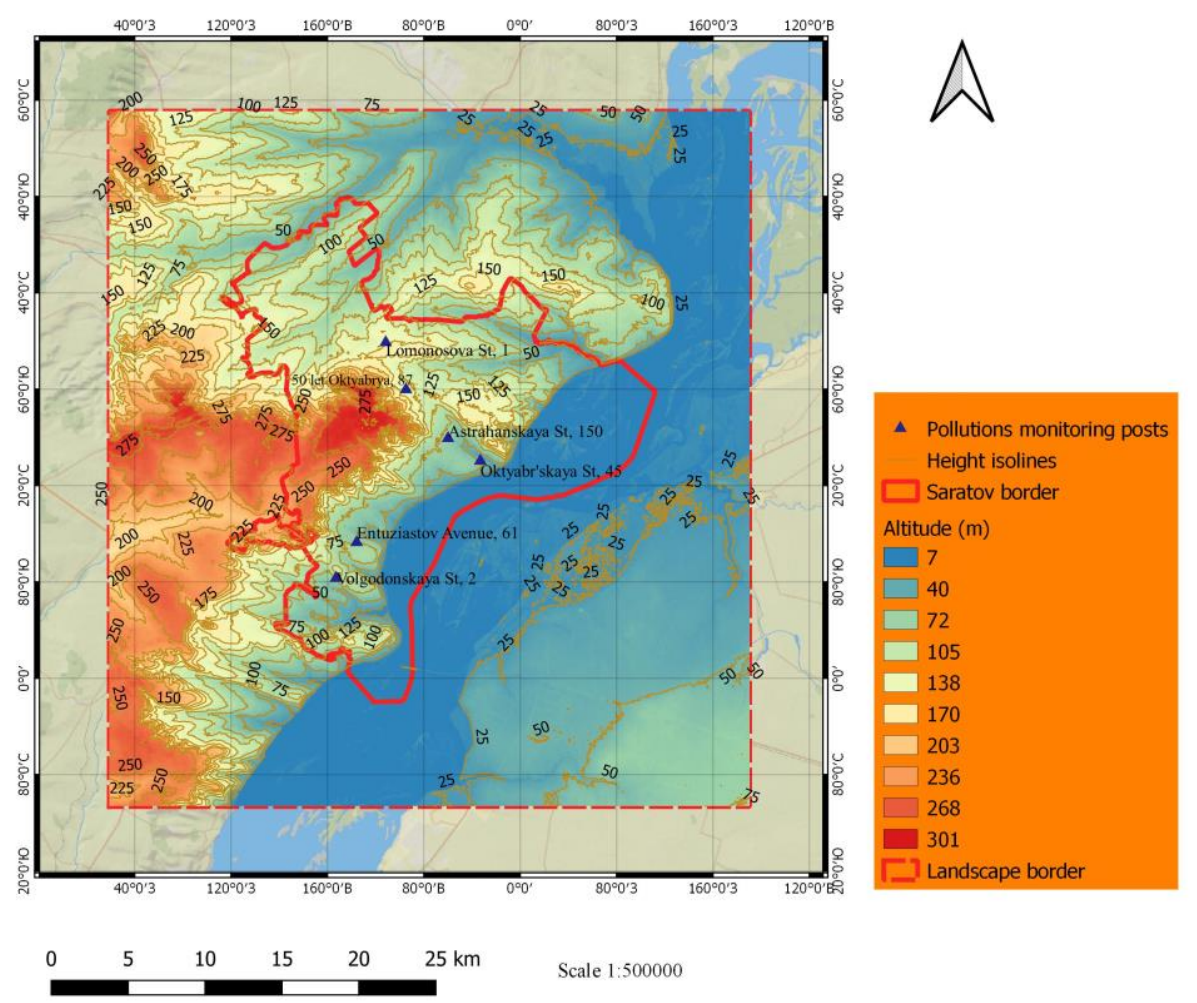

Fig.1. Distribution of air pollution monitoring posts in Saratov by altitude.

The altitudes above sea level for pollution monitoring posts are: PMP 1 (Entuziastov Ave.) - 75 m; PMP 2 (Volgodonskaya str., 2) - 50 m; PMP 5 (Oktyabrskaya Str., 45) - 40 m; PMP 6 (Lomonosov str., 1) - 100 m; PMP 7 (50 let Oktyabrya str., 87) - 105 m; PMP 8 (Astrakhanskaya str., 150) - $70 \mathrm{~m}$. Therefore, all the posts representing the districts of Saratov are situated in the height range from 40 to $105 \mathrm{~m}$, i.e. they are located mainly in the lowland area between the ridges of the Volga Upland. In all monitoring points, the total excesses in the concentrations of components polluting the atmospheric air of the city of Saratov rises from May to October (Fig. 2). This represents a period of increased traffic load on the city's highways during this time frame. An adverse level of pollution (the amount of the total excess of concentrations of pollutants, greater than 1) is specific to the Zavodsky district and Kirovsky districts, where the main traffic flows of the city are 
located. Meanwhile, the distribution of polluting components depends both on the position of the monitoring point above sea level and on the neighborhood of the sources of pollutants entering the atmosphere.

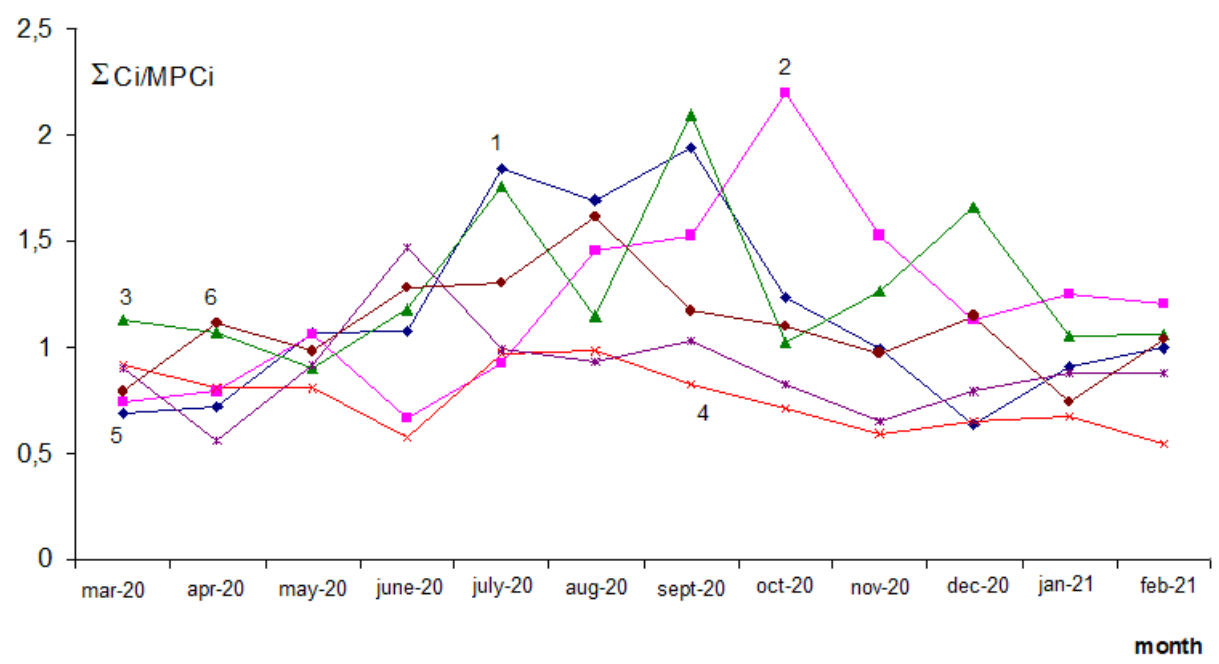

Fig.2. Seasonal dependence of the total excess of concentrations $(\mathrm{Ci})$ of substances polluting the atmospheric air of Saratov. 1-PMP 1; 2- PMP 2; 3- PMP 5; 4- PMP 6; 5- PMP 7; 6- PMP 8.

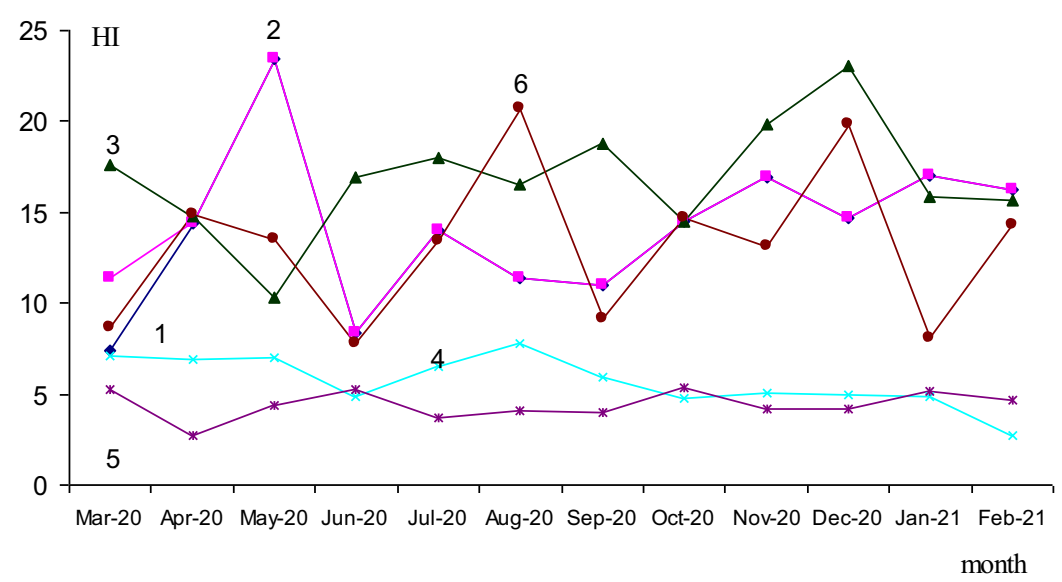

Fig.3. Hazard index distribution due to inhaled exposure of atmospheric air pollutants in the city of Saratov to the human body throughout the year. 1- PMP 1; 2- PMP 2; 3- PMP 5; 4- PMP 6; 5- PMP 7; 6- PMP 8.

As it shown in Fig. 3, the hazard index has a tendency to increase in the warm season (from May to July), as well as in the winter period (January-February). In the first case, this may occur owing to an increase in the intensity of distribution of gas-dust accumulations over the territory of a low-lying city due to an increase in the kinetic energy of particle motion causing an increase in the average monthly temperature. In winter, this condition may be connected with a temperature inversion, when a local pressure distribution is generated. Thus, the temperatures at the surface are lower than at an altitude of several hundred meters above the ground. Meanwhile, due to the disruption of air circulation in the near-surface layer, the accumulation of incomplete fuel combustion products is occurring, 
which creates the smog effect. The greatest contribution to the formation of noncarcinogenic hazard in the monitoring point for the pollution of PMP1 was NO2 and NO, in PMP-2-NO2, NO, H2S, C6H5OH, NH3,HCHO; in PMP - 5-NO2, H2S, HCHO; in PMP 6-NO2, H2S, HCHO; in PMP, located on 50 let Oktyabrya str, 87-NO2, C6H5OH , $\mathrm{NH} 3, \mathrm{HCHO}$; in PMP - 8-NO2, C6H5ON. For all these air pollutants, the target organs were placed in the respiratory system, causing bronchopulmonary diseases. Moreover, phenol leads to changes in the cardiovascular system, as well as in the liver and kidneys. The formaldehyde action is also directed at the immune system. In addition to its own toxic effect on the body, dust has an adsorbing effect on atmospheric pollutants, enhancing their toxic effect by creating a heterogeneity of their distribution in the adsorbed form in relation to the volume.

The anticipated increase in respiratory morbidity due to chronic inhaled exposure to NO2 in children aged 6-7 years ranges from 44 to 79 percent. In this case, the values of the morbidity growth are higher in girls (tabl.1). The increased share in morbidity observed in the Zavodsky and Leninsky districts of Saratov, in relation to posts located at a lower altitude above sea level, may be attributed to the influence of emissions from industrial enterprises and thermal power plants located there.

Table 1. Y values for pollution monitoring posts in February 2021

\begin{tabular}{|l|l|l|l|l|l|l|}
\hline Sex & Post 1 & Post 2 & Post 3 & Post 4 & Post 5 & Post 6 \\
\hline male & 0.7866 & 0.7206 & 0.4415 & 0.7725 & 0.7369 & 0.7820 \\
\hline female & 0.7915 & 0.7264 & 0.4486 & 0.7775 & 0.7424 & 0.7869 \\
\hline
\end{tabular}

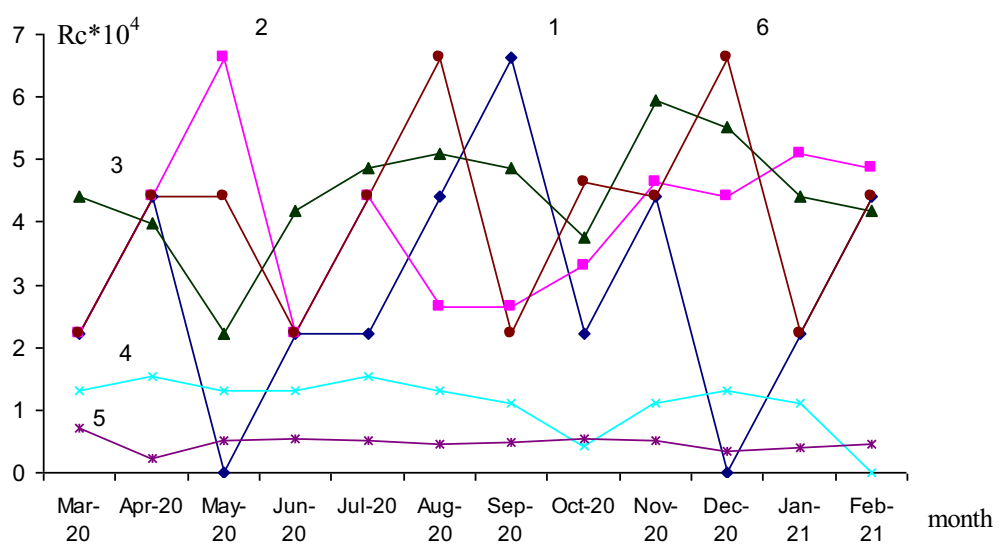

Fig.4. Carcinogenic risk distribution caused by inhaled intake of formaldehyde in the atmospheric air of the city of Saratov on the human body throughout the year. 1-PMP 1; 2-PMP 2; 3-PMP 5; 4-PMP 6; 5-PMP 7; 6-PMP 8.

The carcinogenic risk rises in mid-spring and early autumn, which may be related to an increase in the photochemical activity of lower hydrocarbons, the oxidation product of which is formaldehyde. The carcinogenic risk exceeds the upper limit of the permissible risk and is in the range of $10^{-4}<\mathrm{R}_{\mathrm{c}}<7 \cdot 10^{-4}$ for all pollution monitoring points, except PMP-7 (fig.4). This suggests the formation of smog, which includes formaldehyde. The highest 
values of the carcinogenic risk (posts 1,2,8) consequent to the inhaled intake of this component match the monitoring points located near highways. This may be caused by photochemical processes involving the results of incomplete combustion of fuel in engines, in which formaldehyde is formed.

\section{Conclusion}

The total exceeding of the concentrations of components polluting the atmospheric air of the city of Saratov increases from May to October and is most noticeable in the places of transport interchanges. The health risks related to the inhaled exposure of air pollutants to low-lying cities are identified by the location of the observation point above sea level, as well as by the proximity to the sources of emissions.

The dangerous level of non-carcinogenic health risk due to inhalation of substances polluting the atmospheric air of Saratov (HQ>1) corresponds to nitrogen oxides, hydrogen sulfide, ammonia, and formaldehyde. The carcinogenic health risk associated with the existence of formaldehyde in the air exceeds the upper limit of the permissible risk. Carcinogenic risk caused by inhaled intake of formaldehyde in the body together with inhaled air. The anticipated increase in respiratory morbidity due to chronic inhaled exposure to NO2 in children aged 6-7 years ranges from 44 to 79 percent, while the growup rates are higher in girls.

\section{References}

1. About the current condition of the sanitary and epidemiological well-being of the population in the Russian Federation in 2018: State report, Federal Service for Surveillance of Consumer Rights Protection and Human Well-being, Moscow, 105 (2019)

2. S. Zhong, Z. Yu, W. Zhu, Int J Environ Res Publ Heal, 16(6), 1014 (2019) https://doi.org/10.3390/ijerph16061014

3. O. Raaschou-Nielsen, Z.J. Andersen, R. Beelen, et al. Lancet Oncol, 14(9), 813-822 (2013) https://doi.org/10.1016/S1470-2045(13)70279-1

4. NTT Nhung, H. Amini, C. Schindler. Environ Pollut, 230, 1000-1008 (2017) https://doi.org/10.1016/j.envpol.2017.07.063

5. S. Huang, H. Li, M. Wang. Sci Total Environ, 776, 145968 (2021) https://doi.org/10.1016/j.scitotenv.2021.145968

6. J. Huang, J. Li, P. Yin. Chem, 275, 130041 https://doi.org/10.1016/j.chemosphere.2021.130041

7. M. Guarnieri, JR Balmes. Lanc, 383, 1581-1592 (2014) https://doi.org/10.1016/S01406736(14)60617-6

8. C. Copat, A. Cristaldi, M. Fiore, Environ Res, 191, 110129 (2020) https://doi.org/10.1016/j.envres.2020.110129

9. T. Filippini, KJ Rothman, S. Cocchio, Sci Total Environ, 760, 143355 (2021) https://doi.org/10.1016/j.scitotenv.2020.143355

10. D.U. Kenesary, U.I. Kenesariev, B.S. Turdalieva, A.T. Dosmukhametov and A.U. Kenesary, Bul. KazNMU, 2(4), 38-40 (2014)

11. N.A. Clark, P.A. Demers, C.J. Karr. Environ Health Perspect, 118(2), 284-290 (2010) https://doi.org/10.1289/ehp.0900916 
12. I.A. Neamtiu, S. Lin, M. Chen, C. Roba, E. Csobod, and E.S. Gurzau. Environ Monit Assess, 191(9), 591 (2019). https://doi.org/10.1007/s10661-019-7768-6

13. L.A. Dzhigola, V.V. Shakirova, O.S. Sadomtseva, Ast. Bul of Ec,1, 152-160 (2019)

14. O.Yu. Ustinova, S.L. Valina, I.E. Shtina, O.A. Kobyakova, V.G. Makarova, PH\&LE, 1 (310) (2019)

15. E. Rotondo, F. Chiarelli, Biomed, 8(6), $137 \quad$ (2020) https://doi.org/ 10.3390/biomedicines8060137

16. I. Cimmino, F. Fiory, G. Perruolo, C. Miele, F. Beguinot, P. Formisano, and F. Oriente, Int J Mol Sci, 21(16) (2020) https://doi.org/ 10.3390/ijms21165761

17. H. Reingruber, L. Blas Pontel, Curr Opi in Tox, 9, 28-34 (2018) https://doi.org/10.1016/j.cotox.2018.07.001

18. L.B. Masnavieva, I.V. Kudaeva, N.V. Efimova, Ec. Of. Hum, 6, (2017)

19. L. Yu, B. Wang, M. Cheng, M. Yang, S. Gan, L. Fan, D. Wang, and Chen W. Indoor Air, 30(4), 682-690 (2020). https://doi.org/10.1111/ina.12657.

20. Guidelines R 2.1.10.1920-04. Human health risk assessment from environmental chemicals, (2004)

21. S.M. Novikov, Yu.A. Rakhmanin, N.N. Filatov, Method. recommendations of the MosMR 2.1.9.004-03. Criteria for evaluating the public health risk of the main chemicals polluting the environment, (2003) 